\title{
Modelling catalyst regeneration in an industrial FCC unit
}

\author{
${ }^{*}$ K. K. Dagde, and Y. T. Puyate \\ Department of Chemical/Petrochemical Engineering, \\ Rivers State University of Science and Technology, Port Harcourt, \\ P. M. B. 5080, Port Harcourt, Nigeria
}

\begin{abstract}
Predictive models for process parameters during regeneration of spent catalyst in an industrial fluid catalytic cracking (FCC) unit are presented. The models adopt a twophase theory where the dense region of the regenerator is divided into a bubble-phase and an emulsion-phase. The bubble-phase is modelled as a plug flow reactor, while the emulsion-phase is modelled as a continuous stirred tank reactor (CSTR). Profiles for regenerator-temperature, quantity of coke burnt, and flue gas composition, at different operating conditions are also presented. Model-predictions are compared with plant data and good agreement is obtained. Simulation results indicate that inlet-air velocity and catalyst-bed height have significant influence on the performance of the regenerator. The model-estimated optimum operating conditions of the regenerator are regeneratortemperature of about $1000 \mathrm{~K}$, inlet-air velocity of about $13.5 \mathrm{~m} / \mathrm{s}$, and catalyst-bed height of $13 \mathrm{~m}$.
\end{abstract}

Keywords: Modelling; regenerator; catalytic cracking; coke combustion, catalyst

\section{INTRODUCTION}

Fluid catalytic cracking (FCC) is one of the key processes in modern petroleum refining. While it evolved about 50 years ago, the technology is still being improved upon (Gary \& Handwerk, 2001; Sadaghbeigi, 2000; Jones and Peter, 2006) due to many challenges brought about by environmental regulations, product-quality demands, and economics. Catalytic cracking is similar to thermal cracking except that catalysts facilitate the conversion of the heavier hydrocarbon molecules into lighter products. Use of catalysts in the cracking reaction increases the yield of improved-quality products under much less severe operating conditions than thermal cracking. Since the cracking reactions produce carbonaceous material (referred to as coke) that deposits on the catalyst and very quickly reduces the catalysts reactivity, burningoff the deposited coke with air blown into the regenerator regenerates the catalyst. The regenerator operates at a temperature of about $1000 \mathrm{~K}$ and a pressure of about $241 \mathrm{kPa}$. Combustion of coke is exothermic and it produces large amount of heat that is partially absorbed by the regenerated catalyst and also provides the heat required for vaporization of the feedstock and the endothermic cracking reactions that take place in the riser-reactor. For this reason, FCC units are often referred to as heat balanced (Ahari et al, 2008; Han \& Chang, 2001; Ali et al, 1997).

The regenerator is divided into two regions, namely an upper "dilute region" and a lower "dense region." Most of the models proposed for catalyst regeneration focus on the dense region which is further divided into a bubble-phase and an emulsion-phase (i.e. two-phase model). The advantage of this two-phase model of the dense region is that it describes the whole range of fluidization regimes that covers the operating conditions of various types of FCC regenerators. The earliest models were single-phase, simplecontacting model with plug flow, and dispersion of reacting components with tanks in series (Arthur, 1951; Rowe \& Patridge, 1965; Weiz \& Godwin, 1966). Several workers (Weiz \& Godwin, 1966; Morley \& De-Lasa, 1987; Morley \& De-Lasa, 1988) carried out extensive studies on the kinetics of coke burning reactions for zeolite catalyst and estimated the kinetic parameters for the process but did not apply the kinetic parameters to simulate industrial FCC 
regenerator. Other workers (De-Lasa et al, 1981; Errazu et al, 1979; Krishnaiah et al, 2007) performed steady-state analysis of the regenerator using the two-phase theory (bubblephase rich in gases, and emulsion-phase rich in catalyst particles).

Dynamic models have also been developed in several studies for FCC regenerator. For example, Rao et al. (2004) developed a dynamic model for FCC regenerator in which the dense region was divided into two phases (bubble and emulsion-phases), with both phases modelled as continuous stirred tank reactors (CSTRs) in series. Ali et al. (1997) presented a dynamic model for FCC regenerator that comprises several ordinary differential equations, and also presented analytical solutions of the system of differential equations based on pseudo-steady state conditions. Han and Chung (2001) presented a dynamic model for FCC regenerator with the assumption that the catalysts in the dense bed are in thermal equilibrium with the gases in the bubble-phase, and the gases in both the bubble and emulsion phases are in tubular flow, but most of the parameters used in this model cannot be easily obtained without extensive experimental studies; thus, the model cannot be adapted for the simulation of industrial FCC unit.

In this study, the dense region of the regenerator is also modelled as two phases (bubble and emulsion), but the temperature in the emulsionphase is assumed to be higher than that in the bubble-phase due to the high density of catalyst in the emulsion-phase. In the works of Han and Chung (2001) and Ali et al. (1997), constant superficial velocity was assumed in both the bubble and emulsion phases. However, it is assumed in this study that the gases in the emulsion-phase are at minimum fluidization velocity while the gases in the bubble-phase are above the minimum fluidization velocity, noting that the sum of the velocities in the emulsion and bubble phases equals the constant superficial velocity. The assumption of minimum fluidization velocity in the emulsion-phase is justified by the fact that the catalyst spends longer time in the emulsion-phase (with high catalyst density) than in the bubble-phase (with low catalyst density) which also favours catalytic combustion in the emulsion-phase. The models presented are used to simulate the regenerator of a functional FCC unit in a Nigerian refinery.

\section{Coke combustion kinetics in regenerator-reactor}

Usually, coke is a mixture of different components (carbon, hydrogen, nitrogen, sulphur, etc.), but mainly carbon (Ali et al. 1997). Thus, during catalyst regeneration in FCC unit, coke is burnt to produce carbon monoxide and carbon dioxide (Rao et al. 2004; Arbel et al. (1995). Also, the homogeneous CO combustion reaction taking place in the bubble-phase is assumed to be negligible compared with the catalytic $\mathrm{CO}$ combustion in the emulsion-phase (Ali et al. 1997, Elnashaie \& Elshishini, 1993). Hence, the following irreversible coke combustion reactions occur in the emulsionphase of a regenerator (Weiz \& Godwin, 1966).

$$
\begin{aligned}
& \mathrm{C}+\mathrm{O}_{2} \stackrel{K_{C}}{\longrightarrow} \mathrm{CO}_{2}+\text { Heat } \\
& \mathrm{C}+\frac{1}{2} \mathrm{O}_{2} \stackrel{K_{C}}{\longrightarrow} \mathrm{CO}+\text { Heat } \\
& \mathrm{CO}+\frac{1}{2} \mathrm{O}_{2} \stackrel{K_{\mathrm{CO}}}{\longrightarrow} \mathrm{CO}_{2}+\text { Heat }
\end{aligned}
$$

where $K_{C}$ is the reaction rate constant for coke burning, and $K_{C O}$ is the reaction rate constant for the catalytic $\mathrm{CO}$ combustion. Equation (3) is the "after-burning" reaction which takes place in the dense region if sufficient oxygen is supplied to support it. The reaction which goes to completion in the dense region of a regeneration to fully regenerate the catalyst is called the "controlled-after-burning" reaction. However, $\mathrm{CO}$ burning is usually initiated by using a promoter, which is a catalyst that speeds up the reaction of carbon monoxide to carbon dioxide. The promoter, usually a metal like platinum, is attached to the FCC catalyst during manufacturing. Platinum-based combustion promoters have been utilized in FCC units to catalyze the oxidation of $\mathrm{CO}$ to $\mathrm{CO}_{2}$ for over 30 years (Gary \& Handwerk, 2001; Yang, 2003; Gauthier et al. 2000). The better the dispersion of platinum, the more effective is the combustion of coke. The rate expressions for the component gases in the emulsion-phase are obtained as follows 
Coke (C):

$$
\left(-r_{C}\right)=K_{C} C_{C S} C O_{2}
$$

Oxygen

$\left(\mathrm{O}_{2}\right)$ :

$\left(-r_{O_{2}}\right)=K^{\prime \prime \prime} C_{C S} C O_{2}+K_{C O} C_{C O} C_{O_{2}}^{1 / 2}$

Carbon dioxide $\left(\mathrm{CO}_{2}\right)$ :

$$
\left(-r_{\mathrm{CO}_{2}}\right)=-\mathrm{K}^{\prime \prime} C_{C S} \mathrm{CO}_{2}-\mathrm{K}_{\mathrm{CO}} C_{\mathrm{CO}} C_{\mathrm{O}_{2}}^{1 / 2}
$$

Carbon monoxide (CO):

$$
\left(-r_{C O}\right)=K^{\prime} C_{C S} C O_{2}-K_{C O} C_{C S} C_{O_{2}}^{1 / 2}
$$

where $\left(-r_{C}\right)$ is the rate of coke combustion reaction; $\left(-r_{i}\right)$ are the rates of combustion of individual components of the flue gas; $C_{C S}$ is the molar concentration of coke on spent catalyst; $C_{i}$ are the molar concentrations of the flue gases (i.e. exit gases), with $i=\mathrm{O}_{2}, \mathrm{CO}, \mathrm{CO}_{2}$; and $K,{ }^{\prime} K,{ }^{\prime \prime} K^{\prime \prime \prime}$ are the rate constants in Eqs. (4) - (7) and defined as follows (Han \& Chang, 2001; Ali et al. 1997).

$$
\begin{aligned}
& K^{\prime}=\left(\frac{1}{\alpha+1}\right) K_{C} \text { for } \text { co balance } \\
& K^{\prime \prime}=\left(\frac{\alpha}{\alpha+1}\right) K_{C} \text { for } \mathrm{CO}_{2} \text { balance } \\
& K^{\prime \prime \prime}=\left(\frac{\alpha+2}{2 \alpha+2}\right) K_{C} \text { for } \mathrm{O}_{2} \text { balance }
\end{aligned}
$$

where $\alpha=\mathrm{CO}_{2} / \mathrm{CO}$ is the intrinsic ratio of carbon dioxide to carbon monoxide. The mole fractions of the various flue gases are expressed with respect to the molar concentration of oxygen in the feed air, in the form

$$
y_{O_{2}}^{\prime}=\frac{C_{O_{2}}}{C_{O_{2 F}}}
$$

$$
y_{C O}^{\prime}=\frac{C_{C O}}{C_{O_{2 F}}}
$$

$$
y_{\mathrm{CO}_{2}}^{\prime}=\frac{C_{\mathrm{CO}_{2}}}{C_{\mathrm{O}_{2 F}}}
$$

where $C_{O_{2 F}}$ is the molar concentration of oxygen in the feed air, and the pripge indicates mole fraction.

The regenerator-reactor model: Figure 1 shows a hypothetical representation of FCC regenerator which is divided into two regions - dilute and dense regions, where $\vartheta_{S}$ and $\left(_{k}\right.$ are the volumetric flow rates of spent and regenerated catalyst respectively; $E$ and $B$ are the emulsion and bubble phases respectively; $U_{m f}$ and $U_{a}$ are the minimum fluidization velocity and inlet-air velocity respectively; $C_{i e}$ and $C_{i b}$ are the molar concentrations of flue gases in the emulsion and bubble phases respectively. The "dilute region" is the section between the top of the regenerator and the boundary between the two regions, while the "dense region" extends from the boundary between the two regions to the exit of the regenerator and is divided into a bubble-phase and an emulsion-phase (Kunii \& Levenspel, 1991). The amount of solids entrained in the dilute region is usually very small compared to the total amount of catalyst retained in the regenerator vessel. Most of the coke on the catalyst pellets is combusted in(9)he dense region; that is, full combustion of coke to $\mathrm{CO}_{2}$ is assumed in the dense region. Accordingly, the effect of the dilute region on 1 the overall performance of the regenerator is ignored (Ali et al. 1997). The air distributors, spent catalyst, and cyclones recycle pipes in the emulsion-phase, produce enough turbulence that justifies this phase to be modelled as a continuous stirred tank reactor (CSTR). Hence, it is assumed that the emulsion-phase is a bed at minimum fluidization velocity and coke combustion reactions occur in this phase, while the bubblephase moves as plug flow and exthathges mass and heat with the emulsion-phase without coke combustion reaction due to its deficiency in catalyst particles (Khrisnaiah et al. 2007). In the derivation of the mathematical models for coke 
combustion and catalyst regeneration, the following assumptions are made:

i. Unsteady-state conditions for the energy and coke combustion balances in the emulsion-phase due to high density of catalyst (Ali et al. 1997), and steady-state condition for the same operations in the bubble-phase due to low density of catalyst.

ii. The homogeneous combustion reaction taking place in the bubble-phase is negligible compared with the catalytic $\mathrm{CO}$ combustion in the emulsion-phase (Ali et al. 1997, Morley \& De-lasa, 1988).

Mass balance for coke combustion in the emulsion-phase: Application of the law of conservation of mass to coke combustion in the emulsion-phase based on the above assumptions, gives

$$
\frac{d y_{S}}{d \tau}=\frac{\vartheta_{R} y_{R}-\vartheta_{S} y_{S}}{L_{G I} A_{G}\left(1-\varepsilon_{E}\right) U_{a}}-\left(-r_{C}\right) \frac{L_{G S S}}{U_{a}}-\frac{y_{S}}{L_{G I}} \frac{d L_{G I}}{d \tau}
$$

where the dimensionless rate of change of catalyst-bed height is obtained as

$$
\frac{d L_{G I}}{d \tau}=\frac{\vartheta_{S}-\vartheta_{R}}{A_{G} \rho_{c a t}\left(1-\varepsilon_{E}\right) U_{a}}
$$

The dimensionless variables in equations (14) and (15), and the volume of the regenerator, are defined as

$$
y_{S}=\frac{\rho_{S}}{\rho_{c a t}}, \quad y_{R}=\frac{\rho_{R}}{\rho_{c a t}}, \quad V_{G}=A_{G} L_{G}\left(1-\varepsilon_{E}\right),
$$$$
L_{G I}=\frac{L_{G}}{L_{G S S}}, \quad \tau=\frac{U_{a} t}{L_{G S S}}
$$

where $y_{S}$ is the mass fraction of spent catalyst, $y_{R}$ is the mass fraction of regenerated catalyst, $\rho_{S}$ is the mass density of spent catalyst, $\rho_{R}$ is the mass density of regenerated catalyst, $\rho_{c a t}$ is the mass density of catalyst, $V_{G}$ is the volume of the regenerator, $\tau$ is the dimensionless time, $L_{G I}$ is the dimensionless catalyst-bed height, $L_{G}$ is catalyst-bed height, $A_{G}$ is the crosssectional area of the regenerator, $\varepsilon_{E}$ is the void fraction in the emulsion-phase, and $L_{G S S}$ is the steady-state catalyst-bed height.

Mass balance for gases in the bubble-phase: Application of the law of conservation of mass to gases in the bubble-phase, with the assumptions of no accumulation of gases and without coke combustion reactions, gives the material balance for the flue gases as

$$
\frac{d y_{i b}}{d L_{G I}}=-\left(\frac{K_{b e} L_{G S S}}{U_{a}}\right)\left(1-\varepsilon_{B}\right)\left(y_{i b}-y_{i e}\right)
$$

where $K_{b e}$ is the mass-transfer coefficient between the bubble and emulsion phases, $\varepsilon_{B}$ is the void fraction in the bubble-phase, $y_{i e}$ and $y_{i b}$ are mass fractions of gases in the emulsion and bubble phases respectively and are defines as

$$
y_{i b}=\frac{\rho_{i b}}{\rho_{T G}}, \quad y_{i e}=\frac{\rho_{i e}}{\rho_{T G}}
$$

with $i=\mathrm{O}_{2}, \mathrm{CO}, \mathrm{CO}_{2} ; \rho_{i b}$ and $15 \rho_{i e}$ are the mass densities of gases in the bubble and emulsion phases respectively, and $\rho_{T G}$ is the total mass density of gases in the regenerator.

Mass balance for gases in the emulsionphase: Application of the law of conservation of mass to gases in the emulsion-phase, with coke combustion reactions and accumulation of gases, gives the material balance16pr the flue gases as

$$
\frac{d y_{i e}}{d \tau}=\frac{U_{i e o}\left(y_{i e 0}-y_{i e}\right)}{L_{G I}\left(1-\varepsilon_{E}\right) U_{a}}-\left(-r_{i}\right) \frac{L_{G S S}}{U_{a}} K_{b e}\left(y_{i b}-y_{i e}\right) \frac{L_{G S S}}{U_{a}}
$$

where $U_{i e o}$ is the incipient velocity into the emulsion-phase, $y_{i e o}$ is the initial mass fraction of the respective gases entering the emulsion- 
phase, and $\left(-r_{i}\right)$ are the reaction rates of the flue gases in the emulsion-phase.

Energy balance in the bubble-phase: In the bubble-phase, steady-state operation is assumed because of the high velocity of gases, and it is also assumed that no combustion reaction takes place due to low catalyst density. Application of the law of conservation of energy to gases in the bubble-phase based on the above assumptions, gives the energy balance in this phase as

$$
\frac{d T_{b}^{\prime}}{d L_{G I}}=\frac{H_{b e}\left(T_{b}^{\prime}-T_{e}^{\prime}\right)\left(1-\varepsilon_{B}\right) L_{G S S}}{U_{b}}
$$

with

$$
T_{b}^{\prime}=\frac{T_{b}}{T_{r e f}}, \quad T_{e}^{\prime}=\frac{T_{e}}{T_{r e f}}
$$

where, $T_{b}^{\prime}$ and $T_{e}^{\prime}$ are the dimensionless temperatures in the bubble and emulsion phases respectively, $\quad T_{b}$ is the bubble-phase temperature, $T_{e}$ is the temperature in the emulsion-phase, $T_{\text {ref }}$ is a reference temperature taken to be $960 \mathrm{~K}$ (NHPRC, 1987), $H_{b e}$ is the heat-transfer coefficient between the bubble and emulsion phases, and $U_{b}$ is the bubble velocity.

Energy balance in the emulsion-phase: Application of the law of conservation of energy to coke on spent and regenerated catalysts as well as the gases in the emulsion-phase, with coke combustion reactions, accumulation of gases, and transfer of heat between the bubble and emulsion phases, gives the energy balance in the emulsion-phase as

$$
\begin{aligned}
& \frac{d T_{e}^{\prime}}{d \tau}=\frac{\left(\vartheta_{i e o} \rho_{i e o} C_{p_{i e o}} T_{a o}^{\prime}-\vartheta_{i e} \rho_{i e} C_{p i e} T_{e}^{\prime}\right)}{U_{a} A_{G} L_{G I}\left(1-\varepsilon_{E}\right)\left(\rho_{i e} C_{p i e}+\rho_{R} C_{p_{R}}\right)}+\frac{\left(\vartheta_{S} C_{p_{S}} \rho_{S} T_{R}^{\prime}-\vartheta_{R} C_{p_{R}} \rho_{R} T_{e}^{\prime}\right)}{U_{a} A_{G} L_{G I}\left(\rho_{i e} C_{p i e}+\rho_{R} C_{p_{R}}\right)} \\
& +\frac{\sum_{i=1}^{n}\left[\left(\Delta H_{i e}\right)\left(-r_{i}\right) \rho_{O_{2}}+\left(\Delta H_{C}\right)\left(-r_{C}\right) \rho_{R}\right] L_{G S S}}{\left(\rho_{i e} C_{p i e}+\rho_{R} C_{p_{R}} U_{a} T_{r e f}\right)}+\frac{\gamma H_{b e} L_{G S S}\left(T_{b}^{\prime}-T_{e}^{\prime}\right)}{\left(\rho_{i e} C_{p i e}+\rho_{R} C_{p_{R}}\right) U_{a}}-\frac{T_{e}^{\prime}}{L_{G I}} \frac{d L_{G I}}{d \tau}
\end{aligned}
$$

with

$$
T_{a o}^{\prime}=\frac{T_{a o}}{T_{r e f}}, \quad T_{R}^{\prime}=\frac{T_{R}}{T_{r e f}}
$$

where $\vartheta_{i e o}$ and $\vartheta_{i e}$ are the volumetric flow rates of flue gases at the inlet and outlet of the emulsion-phase; $T_{a o}^{\prime}$ is the dimensionless inlet air temperature of the regenerator, $\rho_{i e o}$ and $\rho_{i e}$ are the mass densities of the flue gases at the inlet and outlet of the emulsion-phase respectively, $\rho_{\mathrm{O}_{2}}$ is the mass density of gas (oxygen) in the emulsion-phase, $C_{\text {pieo }}$ and $C_{\text {pie }}$ are the specific heat capacities of (h) flue gases at the inlet and outlet of the emulsion-phase respectively, $C_{p_{S}}$ and $C_{p_{R}}$ are the specific heat capacities of spent catalyst and regenerated catalyst respectively which are take $\mathbf{Q} \phi$ be equal, $\Delta H_{i e}$ are the heat of reaction of the flue gases in the emulsion-phase, $\Delta H_{C}$ is the heat of reaction for coke combustion, $\gamma$ is the specific area for heat transfer between the bubble and emulsion phases, $T_{R}^{\prime}$ is the dimensionless temperature of the riser, and $T_{R}$ is the riser-temperature. Note that the inlet temperature of the regenerator is partly the temperature of the spent catalysts entering the regenerator from the riser, and partly the inlet ambient air temperature.

Hydrodynamic specifications: The interchange mass-transfer coefficients between the bubble and emulsion phases are related in the form (Kunii \& Levenspel, 1991; Davidson \& Harrison, 1963).

$$
\frac{1}{K_{b e}}=\frac{1}{K_{c e}}+\frac{1}{K_{b c}}
$$

with

$$
K_{c e}=6.77\left(\frac{\varepsilon_{m f} D U_{b r}}{d_{b}^{3}}\right)^{1 / 2}
$$

and

$$
K_{b c}=\frac{4.5 U_{m f}}{d_{b}}+\frac{5.85 D^{1 / 2} g^{1 / 4}}{d_{b}^{5 / 4}}
$$


where $K_{c e}$ is the mass-transfer coefficient between the cloud and emulsion phases, $K_{b c}$ is mass-transfer coefficient between the bubble and cloud phases, $d_{b}$ is the effective bubble diameter, $D$ is the air diffusivity through the catalyst, $g$ is the acceleration due to gravity, $\varepsilon_{m f}$ is the voidage at minimum fluidization, and $U_{b r}$ is the rise-velocity of a single bubble in the bed and is given by (Froment \& Bischoff, 1990).

$$
U_{b r}=0.711\left(g d_{b}\right)^{1 / 2}
$$

Accordingly, the interchange heattransfer coefficients between the bubble and emulsion phases may be expressed as

$$
\frac{1}{H_{b e}}=\frac{1}{H_{c e}}+\frac{1}{H_{b c}}
$$

with (Kunii \& Levenspel, 1991)

$$
H_{b c}=\frac{4.5 U_{m f} \rho_{G o} C_{p g}}{d_{b}}+\frac{5.85\left(K_{G o} \rho_{G o} C_{p g}\right)^{1 / 2} g^{1 / 4}}{d_{b}^{5 / 4}}
$$

where $\rho_{G o}$ is the density of the gas mixture, $C_{p g}$ is the specific heat capacity of the gas mixture, $K_{G o}$ is the thermal conductivity of the gas mixture, $H_{c e}$ is the heat-transfer coefficient between the cloud and emulsion phases, and $H_{b c}$ is the heat-transfer coefficient between the bubble and cloud phases. By comparing the expressions for $K_{b c}$ and $H_{b c}$ above, a corresponding expression for $H_{c e}$ may be obtained through the expression for $K_{c e}$ as

$$
H_{c e}=6.77\left(\frac{K_{G o} \rho_{G o} C_{p g} \varepsilon_{m f} U_{b r}}{d_{b}^{3}}\right)^{1 / 2}
$$

The flow velocities in the analysis are related in the form (Froment \& Bischoff, 1990).

$$
U_{b}=U_{a}-U_{m f}+U_{b r}
$$

where $U_{m f}$ is the minimum fluidization velocity in the emulsion-phase of the regenerator, and $U_{a}$ is the superficial inlet-air velocity into the regenerator. The exit concentrations of the flue gases and exit temperatures from the emulsion and bubble phases are given as (Dagde, 2009)

$$
\begin{aligned}
& y_{O_{2}}=\beta y_{O_{2 b}}+(1-\beta) y_{O_{2 e}} \\
& y_{C O_{2}}=\beta y_{C O_{2 b}}+(1-\beta) y_{C O_{2 e}} \\
& y_{C O}=\beta y_{C O_{b}}+(1-\beta) y_{C O_{e}(27)} \\
& T_{e}=\beta T_{b}^{\prime}+(1-\beta) T_{e}^{\prime}
\end{aligned}
$$

where

$$
\beta=1-\frac{U_{m f}}{U_{a}}
$$

and the subscripts $e$ and $b$ indicate emulsionphase and bubble-phase respectively.

\section{Estimation of kinetic parameters, feedstock and catalyst properties: The kinetic parameters $K_{C}$ and} $K_{C O}$ are not known, and they are functions of temperature generally given by the Arrhenius relationship

$$
K_{i}=K_{i o} \exp (-E / R T)
$$

where $K_{i}$ is the reaction rate constant $(i=\mathrm{C}$, CO), $K_{i o}$ is the pre-exponential constant, $E$ is the activation energy, $R$ is the universal gas constant, and $T$ is the absolute temperature. Table 1 shows the kinetic parameters for coke and carbon dioxide used in this study. The dimensions of some components of a typical FCC unit, and some physical properties of the reacting species, are presented in Tables $2-30$ The heat of reaction of the flue gases and the various combustion reactions were estimated using expressions presented by Han and Chung (2001).

\section{Results and Discussion}

Table 5 shows the comparison between plant data and predictions of the models (Eqs. (17) and (19) combined through Eqs. (32) - (34) for mass fraction 
of exit gases, and Eqs. (20) and (22) combined through Eq. (35) for exit temperature). It may be seen from Table 5 that the predicted data agree reasonably well with the plant data. For proper catalyst regeneration with low carbon content on the regenerated catalyst, and complete burning of $\mathrm{CO}$ to $\mathrm{CO}_{2}$, there must be excess oxygen concentration of 1 to $4 \mathrm{~mol} \%$ (Bai et al. 1998) in the regenerator which is consistent with the plant value and modelprediction in Table 5. Although carbon monoxide was not detected in the flue gas of the plant data (Table 5), the model-predicted $5.7 \mathrm{~mol} \%$ concentration of carbon monoxide in the flue gas is recommended for combustion in the $\mathrm{CO}$ boiler to generate superheated steam and energy for the plant.

Figure 2 shows plots of mole fraction of the flue gases against dimensionless time, indicating that the concentration of oxygen increases rapidly with time to a maximum value of 0.0742 corresponding to a dimensionless time of 0.025 , and then decreases to 0.0312 at a corresponding dimensionless time of unity. We note in Fig. 2 that initial concentrations of oxygen, carbon monoxide, and carbon dioxide were chosen (Han \& Chang, 2001) in order to simulate the models. Thus, the initial rapid increase in the concentrations of theses gases may indicate that the chosen initial concentrations of the gases are less than their 'actual' concentrations at the beginning of coke combustion. However, as the coke combustion process progresses, oxygen from the inlet air reacts with coke on the spent catalyst to produce carbon monoxide and carbon dioxide according to the combustion reactions (1) and (2), so the concentration of oxygen in the exit gases decreases with time while the concentrations of carbon monoxide and carbon dioxide increase with time. But the concentration of carbon monoxide in Fig. 2 increases to a maximum value and then decreases from the maximum value with time. Although the decrease in concentration of carbon monoxide with time after the maximum value may be due to its conversion to carbon dioxide, this conversion process may not be attributed to the presence of significant quantity of oxygen in the regenerator since oxygen also decreases with time during the period of carbon monoxide depletion. Hence, the decrease in concentration of carbon monoxide with time after the maximum value may be due to the contribution of combustion promoter which sustains and speeds up the reaction of carbon monoxide to carbon dioxide.

Figure 3 shows the variations of regeneratortemperature and quantity of coke burnt with dimensionless time. The coke on spent catalyst is burnt continuously leading to its decrease from an initial value of $0.051 \mathrm{wt} . \%$ to about $0.008 \mathrm{wt} . \%$ (at a dimensionless time of unity). The regeneratortemperature increases gradually from an initial value of about $797 \mathrm{~K}$ to $1000 \mathrm{~K}$ (at a dimensionless time of unity). The increase in regenerator-temperature with time is due to accumulation of heat produced by the exothermic coke combustion reactions taking place in the regenerator.

Figure 4 shows the influence of inlet-air velocity on the mole fraction of the flue gases (i.e. oxygen, carbon dioxide, and carbon monoxide) in the regenerator. It may be seen from Fig. 4 that the mole fractions of both oxygen and carbon monoxide decrease as the inlet-air velocity increases, while the mole fraction of carbon dioxide initially decreases slightly from a value of 0.149 at $10.5 \mathrm{~m} / \mathrm{s}$ to 0.138 at $13.5 \mathrm{~m} / \mathrm{s}$, and then increases to a value of 0.168 at $18.5 \mathrm{~m} / \mathrm{s}$. The decrease in the mole fractions of oxygen and carbon monoxide as the inlet-air velocity increases indicates that these gases are consumed in the regenerator and their rates of consumption increase as the inlet-air velocity increases. Since the only sources for consumption of oxygen and carbon monoxide in the regenerator are the coke combustion reactions (1) - (3), it means the rates of these chemical reactions increase as the inlet-air velocity increases. This is similar to the effect of velocity of a drying medium on a drying process where drying rate (especially in the constant-rate period) increases with increase in velocity of the drying medium. As the inlet-air velocity increases, the rate of oxygen supply to the regenerator also increases and the combustion reactions (1) - (3) are enhanced, so that the mole fraction of carbon dioxide is expected to increase as the inlet-air velocity increases and not for the mole fraction of carbon dioxide to decrease as the inlet-air velocity increases to $13.5 \mathrm{~m} / \mathrm{s}$ as obtained in Fig. 4 . Thus, the initial decrease in concentration of carbon dioxide suggests that both carbon dioxide and carbon monoxide are not produced in the regenerator by the combustion reactions for inlet-air velocity less than $13.5 \mathrm{~m} / \mathrm{s}$. In other words, combustion of coke and carbon monoxide do not take place in the regenerator at inlet-air velocity less than $13.5 \mathrm{~m} / \mathrm{s}$, such that the minimum inlet-air velocity required to initiate combustion reactions in the regenerator may be taken to be $13.5 \mathrm{~m} / \mathrm{s}$. For proper catalyst regeneration and complete burning of carbon monoxide to carbon dioxide, the inlet-air velocity must always be in excess of the "theoretical" or exact amount required (NPHRC, 1987). Air velocity must 
be adjusted to ensure proper coke combustion and catalyst regeneration without "after-burning or "behind-in-burning" reactions.

Figure 5 shows the effect of inlet-air velocity on the regenerator-temperature and quantity of coke burnt, indicating that the quantity of coke burnt increases as the inlet-air velocity increases. This is due to increase in the rate of coke combustion reactions resulting from a corresponding increase in the rate of oxygen supply to the regenerator as the inlet-air velocity increases, which is consistent with the trend of oxygen profile in Fig. 4. The regenerator-temperature increases to a maximum value of about $1000 \mathrm{~K}$ as the inlet-air velocity increases to corresponding value of about $14.0 \mathrm{~m} / \mathrm{s}$, and then remains approximately constant at this maximum temperature for higher values of the inlet-air velocity. At the optimum regenerator-temperature, the operation of the regenerator is said to have reached 'total combustion regime' and any carbon monoxide present in the regenerator is converted to carbon dioxide. At inletair velocity above the optimum value, the spent catalyst spends less time (low residence time of spent catalyst) in the regenerator caused by channelling and by-passing effect inherent in typical fluidized-bed reactors (Cheremisinoff \& Cheremisinoff, 1984). Some portion of the spent catalyst also escapes with the flue gases without proper contact with the combustion air. It is very essential that the coke be burned off the spent catalyst at the same rate as it is produced in the riser reactor. This can be achieved by maintaining a small amount of excess oxygen in the regenerator above that which is required to burn the coke. When all the coke is not burnt, the unit is said to be "behind-inburning' with the result that the catalyst turns grey (Bai et al. 1998) and loses its activity thereby decreasing the yield of desired products in the riser. To avoid this, the velocity of air entering the regenerator should be increased gradually.

Figure 6 shows the effect of catalyst-bed height on the mole fractions of the flue gases. It is obvious from Fig. 6 that the mole fraction of carbon dioxide decreases as the catalyst-bed height increases, reaching a minimum value of about 0.11 at catalystbed height of about $14 \mathrm{~m}$; thereafter, the mole fraction of carbon dioxide increases slightly as the catalyst-bed height increases. Unlike carbon dioxide, the mole fraction of carbon monoxide increases as the catalyst-bed height increases, reaching a maximum value of 0.162 at catalyst-bed height of about $14 \mathrm{~m}$; thereafter, the mole fraction of carbon monoxide decreases as the catalyst-bed height increases. The mole fraction of oxygen, on the other hand, increases continuously as the catalyst-bed height increases. At low catalyst-bed height, the quantity of coke to be burnt is small and there is sufficient amount of oxygen supply from the inlet air (at constant velocity) so that all three combustion reactions (1) - (3) take place in the regenerator. As the catalyst-bed height increases, the quantity of coke to be burnt also increases, but $\mathrm{CO}$ combustion reaction (3) decreases due to insufficient amount of oxygen to support it, so that incomplete combustion of coke to produce $\mathrm{CO}$ (i.e. combustion reaction (2)) prevails in the regenerator. Hence, as the catalystbed height increases, the concentration of oxygen in the regenerator increases partly due to incomplete combustion of coke and partly from its constant supply from the inlet-air, the concentration of carbon dioxide decreases, while the concentration of carbon monoxide increases. At catalyst-bed height of about $14 \mathrm{~m}$, the concentration of oxygen in the regenerator is high enough to support and sustain $\mathrm{CO}$ combustion reaction (3) to form carbon dioxide, so that the concentration of carbon monoxide decreases while the concentration of carbon dioxide increases slightly for catalyst-bed height greater than $14 \mathrm{~m}$ as obtained in Fig. 6.

Figure 7 shows the effects of catalyst-bed height on the quantity of coke burnt and the regeneratortemperature. It may be seen from Fig. 7 that the quantity of coke burnt decreases as the catalyst-bed height increases, which is due to increase in the quantity of coke to be burnt with constant supply of oxygen from the inlet-air. At catalyst-bed height of about $14 \mathrm{~m}$ and higher, the quantity of coke burnt is theoretically zero, meaning that almost no coke on the spent catalyst is burnt for this range of catalystbed height (see Fig. 7). Hence, the lower the catalystbed height, the better and more effective the coke burning process, such that the optimum catalyst-bed height for regeneration of spent catalyst may be estimated from Fig. 7 to be $13 \mathrm{~m}$, beyond which, negligible coke combustion takes place. Figure 7 also indicates that the regenerator-temperature increases as the catalyst-bed height increases, reaching a maximum value of about $1150 \mathrm{~K}$ at catalyst-bed height of about $13 \mathrm{~m}$; thereafter, the regeneratortemperature decreases as the catalyst-bed height increases. The increases in regenerator-temperature as the catalyst-bed height increases is, of course, due to the exothermic combustion reactions (1) - (3) taking place in the regenerator. At the maximum temperature of about $1150 \mathrm{~K}$, the operation of the 
Am. J. Sci. Ind. Res., 2013, 4(3): 294-305

regenerator has reached "total combustion regime" and any carbon monoxide present in the regenerator is converted to carbon dioxide. The decrease in regenerator-temperature for catalyst-bed height greater than $13 \mathrm{~m}$ indicates that some of the coke on the spent catalyst are not burnt, which reduces both the heat produced by the exothermic combustion reactions and the temperature of the regenerator for the said range of catalyst-bed height as obtained in Fig. 7. It may be observed that the maximum regenerator-temperature in Fig. 7 is higher than its maximum value of about $1000 \mathrm{~K}$ in Figs. 3 and 5 , where the difference may be attributed to additional heat resulting from the effect of catalyst-bed height on the combustion reactions (1) - (3) when the inletair velocity is maintained at a constant value.

Table 1. Kinetic parameters for coke burning (Morley \& De-Lasa, 1987).

\begin{tabular}{|l|l|c|}
\hline Reaction & $\begin{array}{l}\text { Pre-exponential } \\
\text { constant }\end{array}$ & $\begin{array}{c}\text { Activation } \\
\text { energy } \\
(\mathrm{kJ} / \mathrm{kmol})\end{array}$ \\
\hline $\begin{array}{l}\text { Coke } \\
\text { combustion }\end{array}$ & $\begin{array}{l}1.4 \times 10^{8} \quad \mathrm{~m}^{3} \\
224.99 \\
\mathrm{kmol}^{-1} \mathrm{~s}^{-1}\end{array}$ & \\
\hline $\begin{array}{l}\text { CO catalytic } \\
\text { combustion }\end{array}$ & $\begin{array}{l}247.755 \\
\left.\mathrm{kmol}^{0.5} \mathrm{~s}^{-1} \mathrm{~kg}^{-1}\right)^{1.5}\end{array}$ & 70.74 \\
\hline
\end{tabular}

Table 2. Dimensions of some components of FCC unit (NPHRC, 1987).

\begin{tabular}{|l|c|c|}
\hline \multicolumn{1}{|c|}{ Component } & Height (m) & Diameter (m) \\
\hline $\begin{array}{l}\text { Regenerator- } \\
\text { reactor }\end{array}$ & 35.45 & 9.8 \\
\hline Riser-reactor & 22.9 & 2.9 \\
\hline $\begin{array}{l}\text { Particle } \\
\text { separator vessel }\end{array}$ & 24.49 & 2.4 \\
\hline
\end{tabular}

Table 3. FCC operating conditions (NPHRC, 1987).

\begin{tabular}{|l|l|c|}
\hline Material & Flow rate & Inlet Temperature \\
\hline Gas-oil & $68.05 \mathrm{~kg} / \mathrm{s}$ & $797 \mathrm{~K}$ \\
\hline Air & $43.2466 \mathrm{~m}^{3} / \mathrm{s}$ & $370 \mathrm{~K}$ \\
\hline Catalyst & $480.49 \mathrm{~kg} / \mathrm{s}$ & $975 \mathrm{~K}$ \\
\hline
\end{tabular}

Table 4. Some physical properties and heat of reaction of reacting species (Ali et al. 1997).

\begin{tabular}{|l|l|}
\hline Parameter & Value \\
\hline Density of air & $1.03 \mathrm{~kg} / \mathrm{m}^{2}$ \\
\hline Specific heat capacity of air & $1.206 \mathrm{~kJ} / \mathrm{kg} \mathrm{K}$ \\
\hline $\begin{array}{l}\text { Bubble-emulsion mass-transfer } \\
\text { coefficient }\end{array}$ & $0.5 \mathrm{~s}^{-1}$ \\
\hline $\begin{array}{l}\text { Bubble-emulsion heat-transfer } \\
\text { coefficient }\end{array}$ & $0.84 \mathrm{~kJ} / \mathrm{m}^{2} \mathrm{~s} \mathrm{~K}$ \\
\hline Bulk density of catalyst & $975 \mathrm{~kg} / \mathrm{m}^{3}$ \\
\hline
\end{tabular}

\begin{tabular}{|l|l|}
\hline Particle size of catalyst & $7.5 \times 10^{-6} \mathrm{~m}$ \\
\hline Specific heat capacity of catalyst & $1.15 \mathrm{~kJ} / \mathrm{kg} \mathrm{K}$ \\
\hline Holdup in the regenerator & $5000-70000 \mathrm{~kg}$ \\
\hline
\end{tabular}

Table 5. Comparison between plant data (NHPRC, 1987) and model predictions.

\begin{tabular}{|l|c|c|}
\hline Parameter & Plant data & $\begin{array}{c}\text { Model } \\
\text { prediction }\end{array}$ \\
\hline $\begin{array}{l}\text { Regenerator } \\
\text { Temperature }(\mathrm{K})\end{array}$ & 1016.48 & 1015.07 \\
\hline $\mathrm{Coke}($ wt. \%) & 0.007 & 0.00686 \\
\hline $\mathrm{CO}_{2}(\mathrm{~mol} \%)$ & 0.16 & 0.161 \\
\hline $\mathrm{O}_{2}(\mathrm{~mol} \%)$ & 0.03 & 0.0312 \\
\hline $\mathrm{CO}(\mathrm{mol} \%)$ & 0 & 0.0568 \\
\hline
\end{tabular}

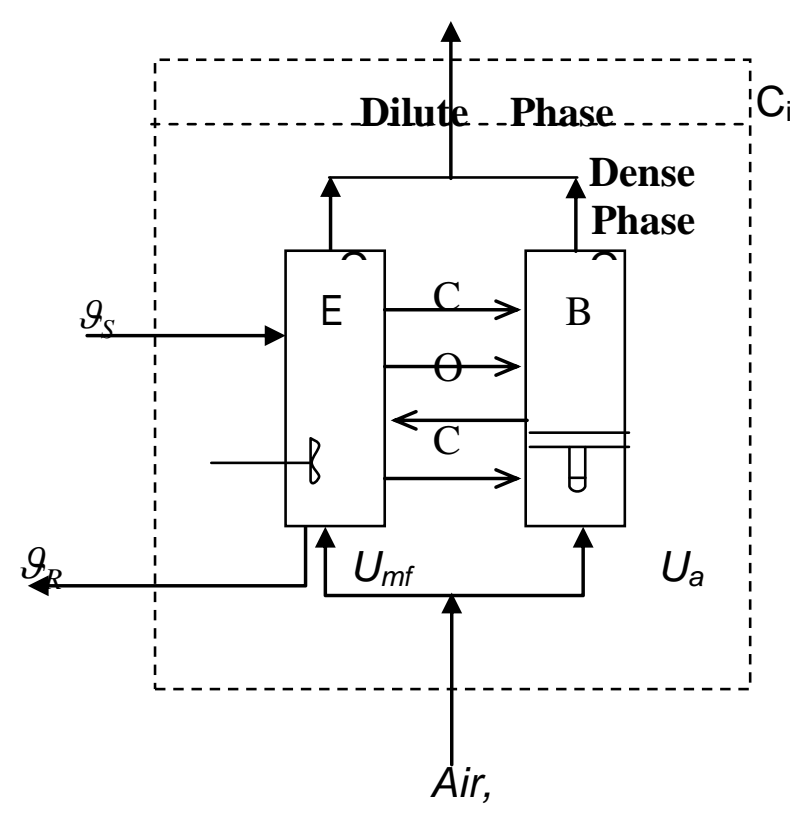

Fig. 1. Hypothetical representation of a regenerator.

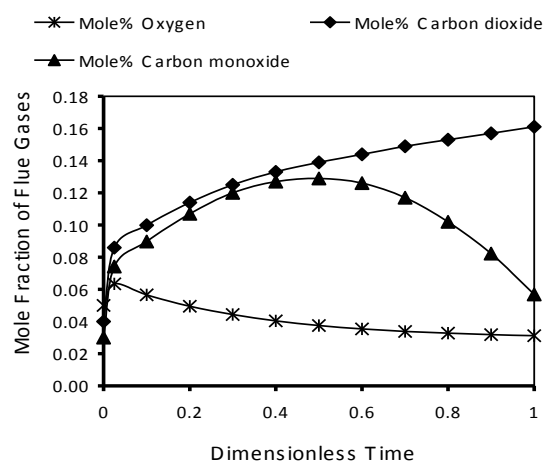

Fig. 2. Variation of mole fraction of flue gases with dimensionless time. 
Am. J. Sci. Ind. Res., 2013, 4(3): 294-305

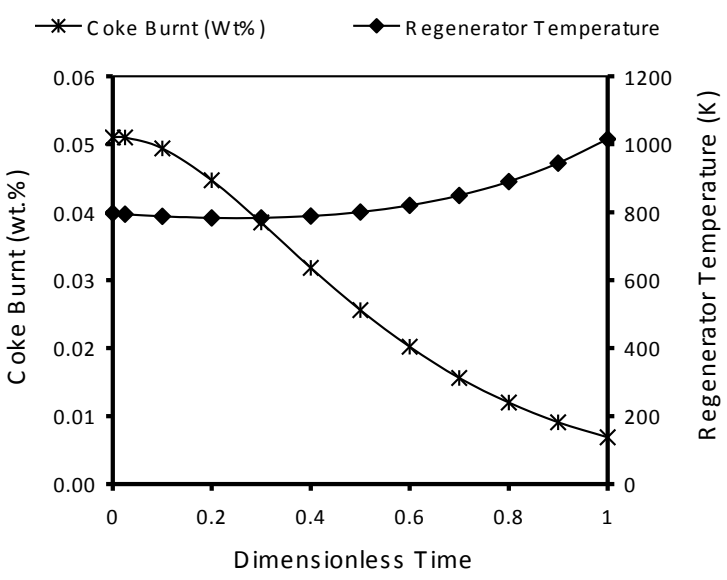

Fig. 3. Variations of quantity of coke burnt and regenerator-temperature with dimensionless time.

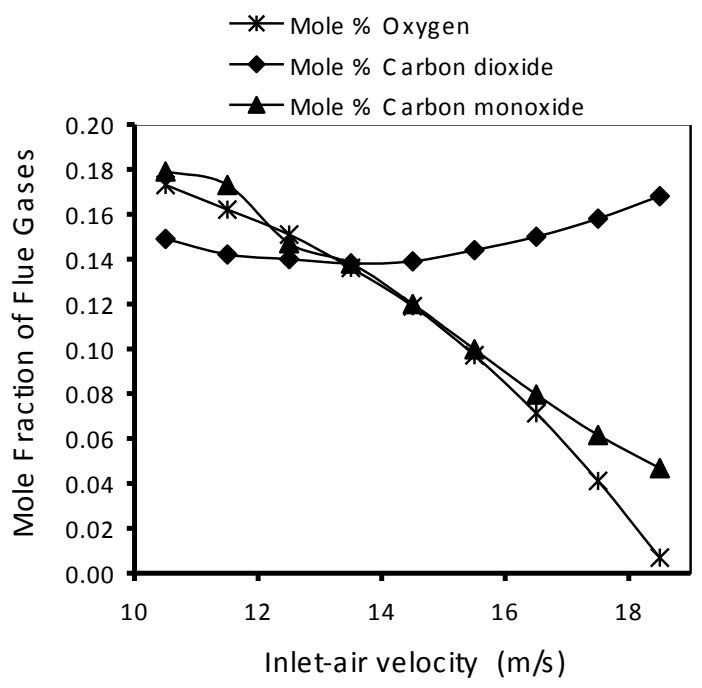

Fig. 4. Variation of mole fraction of flue gases with inlet-air velocity.

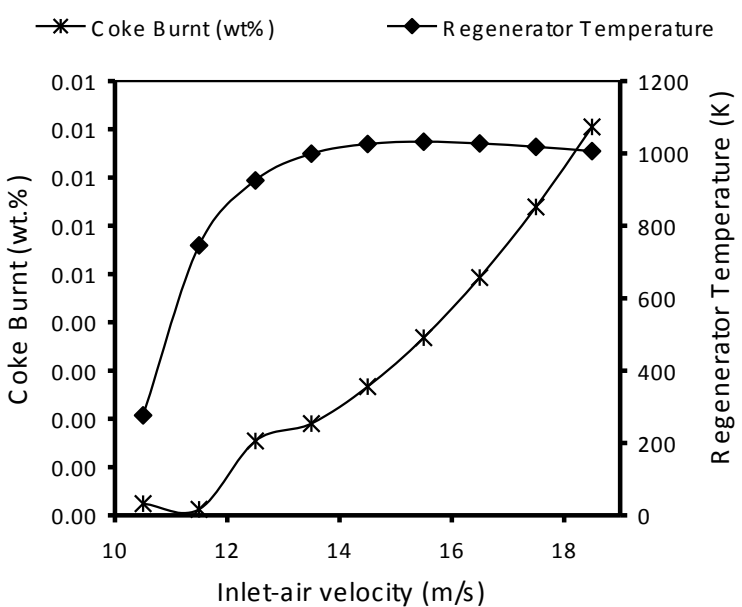

Fig. 5. Variations of quantity of coke burnt and regenerator-temperature with inlet-air velocity.

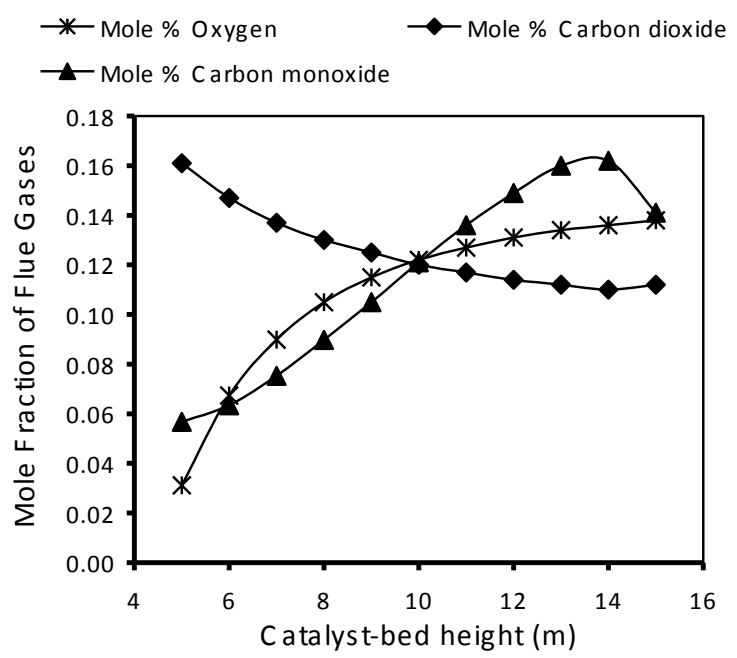

Fig. 6. Variation of mole fraction of flue gases with catalyst-bed height. 


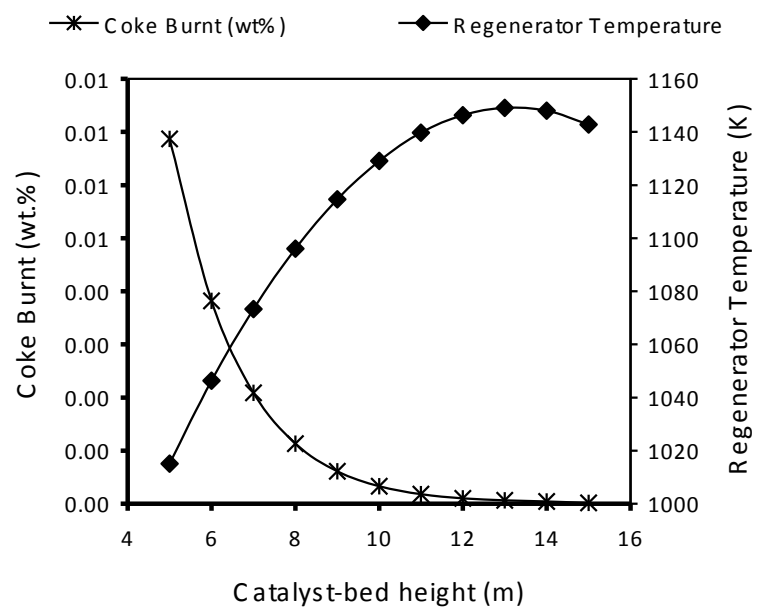

Fig. 7. Variations of quantity of coke burnt and regeneratortemperature with catalyst-bed height.

CONCLUSION: Models which incorporate coke combustion kinetics and hydrodynamic parameters have been developed for simulation of industrial FCC regenerator. Profiles for regenerator-temperature, quantity of coke burnt, and flue gas composition, at different operating conditions have also been presented. FCC catalyst regeneration is a very complex process and many factors (solid mixing, inlet-air velocity, temperature of spent catalyst, carbon content on spent catalyst, etc) influence the performance of the regenerator. Simulation results indicate that catalyst-bed height and inlet-air velocity have significant effects on catalyst regeneration process. Temperature plays a very important role in the regeneration of spent catalyst. It is preferable to maintain an optimum temperature of the regenerator that gives high reaction rate of coke combustion and low carbon content on regenerated catalyst. But caution should be taken not to operate the regenerator at such a low temperature that would quench the reaction or at such a high temperature that the FCC catalyst becomes permanently deactivated due to steam generated from hydrogen combustion (Garry \& Handwerk, 2001, Bai et al. 1998).

\section{REFERENCES}

Ahari J. S., A. Farshi and K. Forsat, "A Mathematical Modeling of the Riser Reactor in Industrial FCC Unit." Petroleum and Coal, 50(2), 15-24 (2008).
Ali, H., Rohani, S., Corriou, J. P. (1997) "Modeling and Control of a Riser Type Fluid Catalytic Cracking (FCC) Unit." Transactions of the Institution of Chemical Engineers, 75, Pp $401-412$.

Arbel, A. Z., Huang, Z., Rinard, I. H., Shinnar, R., Sapre, A. V. (1995) "Dynamics and Control of Fluid Catalytic Crackers-Modelling of the Current Generation FCC's", Industrial Engineering Chemical Resources, 34, pp. $1228-1243$.

Arthur, J.R. (1951) "Reactions between Carbon and Oxygen". Transaction of Faraday Society, 47, pp. 164178

Bai, D., Zhu, J. X., Yin, Y., Yu, Z (1998) "Simulation of FCC Catalyst Regeneration in a Riser Regenerator". Chemical Engineering Journal, 71, pp. 97 - 109.

Cheremisinoff, N.P., Cheremisinoff, P.N. (1984) Hydrodynamics of gas-solid fluidization. Gulf Publishing Company Book Division, Houston, 1984.

Dagde, K.K. (2009) Development of models for the simulation of fluid catalytic cracking reactors. PhD Thesis, Department of Chemical/Petrochemical Engineering, Rivers State University of Science and Technology, Port Harcourt.

Davidson, J. F., Harrison, D. (1963)“. Fluidized Particles”, Cambridge University Press, Newyork, 984.

De-Lasa, H.I., Errazu, A.F., Barreiro E., Solioz, S.(1981) "Analysis of Fluidized BednCatalytic Cracking Regenerator Models in an Industrial Scale Unit" Canadian Journal of Chemical Engineering, 59, pp. 549-553

Elnashaie, S.S.E.H., Elshishini, S.S. (1993) "Digital Simulation of Industrial Fluid Catalytic Cracking Units IV: Dynamic Behaviour". Chemical Engineering Science, 48, pp. 567-583.

Errazu, A.F., De Lasa, H.I.,Sarti, F. (1979) "A Fluidized Bed Catalytic Cracking Regenerator Model - Grid Effects", Canadian Journal of Chemical Engineering, 57, pp. 191-197.

Froment, G. F., Bischoff, K. B. (1990). "Chemical Reactor Analysis and Design", $2^{\text {nd }}$ Ed.,John Willey \& Sons Inc. USA, pp. $566-602$.

Gary, J.H. and Handwerk, G.E. (2001). Petroleum Refining: Technology and Economics, $4^{\text {th }}$ Edition. CRC Press. New York

Gauthier, T., Bayle, J.,Leroy, P. (2000) "FCC: Fluidization Phenomena and Technologies", Oil and Gas Science and Technology, 55 (2), pp. 187-207 
Han, I. S., Chang, C.B. (2001) "Dynamic Modeling and Simulation of a Fluidized Catalytic Cracking Process. Part 1: Process Modelling", Chemical Engineering Science, 56, pp. 1951-1971.

Jones, D.S.J. and Peter P. Pujado, P.P. (2006). Handbook of Petroleum Processing, First Edition. Springer. London .

Krishnaiah D., Gopikrishna V., Awang B. and Rosalam S., "Steady State Simulation of a Fluid Catalytic Cracking Unit", Journal of Applied Science, 2007, 7(15), pp. 2137-2145.

Kunii, D., Levenspiel, O. (1991) "Fluidization Engineering" Butterword - Heinemann, London, 459 - 474.

Morley, K., De Lasa, H. I. (1987) "On the Determination of Kinetic Parameters for the Regeneration of Cracking Catalyst". Canadian Journal of Chemical Engineering, 65 , pp. $773-777$.

Morley, K., De Lasa, H. I. (1988) "Regeneration of Cracking Catalyst Influence of the Homogenous CO Post
Combustion Reaction", Canadian Journal of Chemical Engineering, 66, pp. $428-432$.

NPHRC, (1987) New Port Harcourt Refinery Company: Specific Course for Senior Staff, Area 3, Process Description 1, Comerint.

Rao, R.M., Rengaswarmy, R., Suresh, A. K., Balaraman, K. S. (2004) "Industrial Experience with Object Oriented Modeling FCC Case Study", Trans IchemE, Part A, Chemical Engineerng Research and Design, 82 (A4): pp. $257-552$.

Rowe, P.N., Patridge, B.A. (1965) "An X-ray Sudy of Bubbles in Fluidized Beds". Transaction of Industrial Chemical Engineering, 43: 157

Sadeghbeigi, R. (2000). Fluid Catalytic Cracking Handbook, 2nd Edition. Gulf Publishing, New York.

Weiz, P.B., Godwin, R.B.(1966) "Combustion of Carbonaceous Deposits within Porous Catalyst Particles II, Intrinsic Burning Rate". Journal of Catalysis A, 6: 227-238

Yang,W.C. (2003) "Handbook of fluidization and Fluid Particle Systems",CRC Press, London 